\title{
Nature of observed temperature changes across the United States during the 20th century
}

\author{
Paul C. Knappenberger ${ }^{1, *}$, Patrick J. Michaels ${ }^{2}$, Robert E. Davis ${ }^{2}$ \\ ${ }^{1}$ New Hope Environmental Services, Charlottesville, Virginia 22903, USA \\ ${ }^{2}$ Department of Environmental Sciences, University of Virginia, Charlottesville, Virginia 22903, USA
}

\begin{abstract}
The annual temperature history of the United States during the 20th century shows 3 distinct periods of change: warming from 1900 until about 1940, cooling from 1940 to 1969, and warming from 1970 to the present. The characteristics of daily temperature change during these 3 periods are very different. The first 2 periods are marked by a tendency toward more temperature extremes - higher extreme maxima during the first period, and lower extreme minima during the second. In contrast, the warming during the most recent period, often used as evidence of humaninduced climate change, is characterized by temperature moderation-the pattern of temperature rise exhibits a strong, preferential warming of the coldest days of the year.
\end{abstract}

KEY WORDS: Climate change $\cdot$ Daily temperature trends $\cdot$ United States

\section{INTRODUCTION}

During the past $100 \mathrm{yr}$, observations indicate that the annual average surface air temperature for the 48 contiguous United States has increased at a rate of about $0.04^{\circ} \mathrm{C}$ decade $^{-1}$ (Karl et al. 1996). However, this observed temperature rise has not been constant; instead, it is marked by 3 distinct periods of change. From 1900 to 1939 , annual temperatures rose at a rate of $0.18^{\circ} \mathrm{C}$ decade $^{-1}$. This rise was followed by a temperature decline of $0.12^{\circ} \mathrm{C}_{\text {decade }}{ }^{-1}$ from 1940 to 1969 . From 1970 to 1997 , the temperature again rose at the same rate $\left(0.19^{\circ} \mathrm{C}\right.$ decade $\left.^{-1}\right)$ as in the early century rise (Fig. 1). This pattern of temperature change is also present in global temperature records (e.g., Stott et al. 2000). The most recent rise in temperature is often identified as a signal of anthropogenic alterations to the atmospheric composition of greenhouse gases (e.g., Mann et al. 1998, Tett et al. 1999, Crowley 2000, Stott et al. 2000) and as support for climate model projections of future conditions. These projections have been used by the United Nations Intergovernmental

*E-mail: pck4s@nhes.com
Panel on Climate Change (IPCC) and in the recent United States National Assessment (USNA) of the potential consequences of climate change to suggest that the future will be one with increasing temperature extremes and related consequences such as increased heat-related human mortality, spreading tropical diseases, more severe droughts, more intense precipitation events, and greater agricultural stress (IPCC 1996, 2001, USNA 2000).

Most of these consequences result from climate model output suggesting that a warmer climate is a more extreme climate (IPCC 1996, Easterling et al. 2000, IPCC 2001). However, before the model projections should be embraced by the IPCC or the USNA teams, or can be considered a useful basis for policy or planning decisions, the models should be extensively verified. Observational studies, therefore, should be carried out at a temporal scale appropriate for performing such verifications. Since most extreme events, by definition, occur on a rather fine temporal scale, studies looking for changes in such events need to incorporate data collected on a similarly fine scale. For example, attempting to assess changes in temperature extremes using monthly data may miss many of the important aspects of how that change took place and 


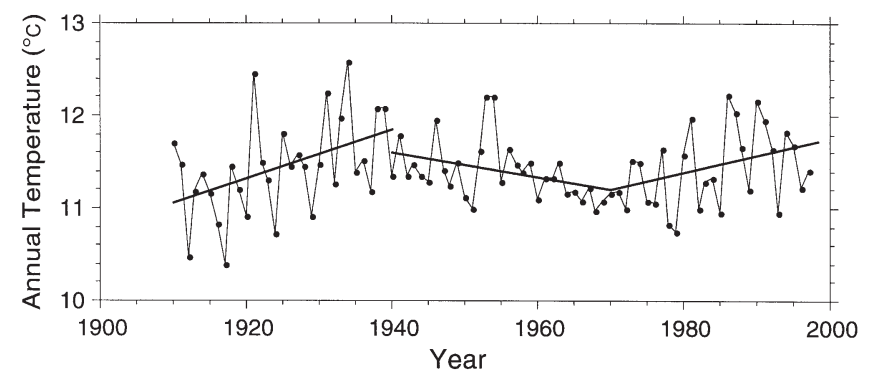

Fig. 1. United States temperature history from 1910 to 1997 showing the pattern of temperature change marked by successive periods of increasing (1910-1939), decreasing (1940-1969), and then increasing (1970-1997) trends

would be insufficient for use in model verifications. Therefore, in order to capture the temporal patterns of temperature change observed across the United States during the 20th century at a scale against which projections of changes in extremes can be judged, we examined trends in daily observations of maximum and minimum temperatures for a collection of stations across the country.

\section{DATA AND ANALYSES}

Our analysis focused on daily temperature trends over the United States within 3 successive time periods covering most of the 20th century: 1910-1939, 1940-1969, and 1970-1997. These periods were chosen from the available data to be of roughly equal length and to best isolate the different temperature patterns, in terms of both trends and break points, that characterize the US temperature record over the course of the 20th century. Observations show that there was a strong warming trend of similar magnitude in the first and last periods, while a cooling trend was present in the middle period (Fig. 1). This pattern of temperature change is well recognized in the US temperature record (e.g., Karl et al. 1995, 1996). While the magnitude of the trends within each period varies across different regions of the United States, the pattern of successive periods of warming, cooling, and warming is generally preserved.

The data used in our analysis were the maximum and minimum temperature observations contained in the 1062-station version of the United States Historical Climate Network daily data for the 48 contiguous United States (HCN/D) (Easterling et al. 1999). The spatial density, daily resolution, and long period of observations make this data set especially useful for the detection and characterization of regional temperature changes across the United States. This data set is an expansion and update of the original 138-station
HCN/D database (Hughes et al. 1992). The expanded database includes much improved spatial density and coverage, although data quality and control are not as strict.

The reduction in data quality and control, however, potentially introduces changes in these data that are not related to climate variability. Sources of these nonclimatological signals include time of observation changes (Baker 1975, Schaal \& Dale 1977, Karl et al. 1986), station moves, urbanization (Karl et al. 1988, Balling \& Idso 1989), and instrument changes (Quayle et al. 1991). It is possible to isolate several of these factors within this data set and to select stations that are free from their effects. To do this, we examined the station history for each station that had a sufficiently long period of record within each of our analysis periods. An adequate period of record was defined to be one with valid data for at least $90 \%$ of the total number of years in an analysis period. Up to 10 non-consecutive missing daily observations were allowed in a valid year. These missing values were interpolated as the linear average between the temperature measured on the preceding and following days. A year containing successive missing daily observations, or more than 10 non-successive days with missing observations, was removed from the analysis. Once stations with adequate data were identified, we then checked for consistency in station location, observation time, and instrument type within each analysis period. We eliminated stations that had station moves of more than $0.1^{\prime}$ of longitude or latitude or an elevation change of more than $6 \mathrm{~m}$. We also eliminated those stations that had a time of observation change of more than $1 \mathrm{~h}$. And lastly, during the 1970-1997 period of study, we removed those stations where the liquid-in-glass thermometers in Cotton Region Shelters that were historically used to record daily maximum and minimum temperatures in the Cooperative Station Network were replaced with a thermistor-based temperature observing system (Maximum-Minimum Temperature System or MMTS). This changeover was begun in the mid1980s.

For each of the remaining stations within each analysis period, the daily data within each year were ranked from the coldest to the warmest. The data were then collected into 365 annual time series for each temperature variable (maximum and minimum temperatures) - 1 time series for each ranked day of the year. Note that these time series do not have a consistent ranking in time (e.g., the Julian day is not constant), but instead have a consistent ranking in temperature (a time series of the first coldest day of each year, a separate time series for the second coldest day of each year, etc.). An ordinary least-squares regression line was then fitted through each of the 365 time series. 
Within each analysis period, we averaged the leastsquares trends from all available stations within 7 roughly equal-area geographic regions across the United States for each ranked day. Regional averages were used to reduce the effects of spatial inhomogeneity of the station distribution, while still allowing some illustration of regional variation of change.

Through this data selection method, we effectively eliminated most non-climatological effects except for land-use changes (including urbanization). The identification and removal of an urbanization signal are extremely difficult, and there exists no method that assures success. Researchers have applied many dif- ferent techniques to monthly data and have reported somewhat, but not completely similar, results (e.g., Karl et al. 1988, Balling \& Idso 1989, Gallo et al. 1999). No studies have attempted to identify, much less adjust for, urbanization influences on a daily scale on anything more than a case-study basis since the magnitude of the urban effect is dependent not only on the physical surroundings but also on the daily weather (e.g., Landsberg 1981, Oke 1987). Because of these severe limitations, we were unable to account for urban influences in our data set. It is the general consensus of previous research that urbanization raises nighttime temperatures and has little effect on daytime

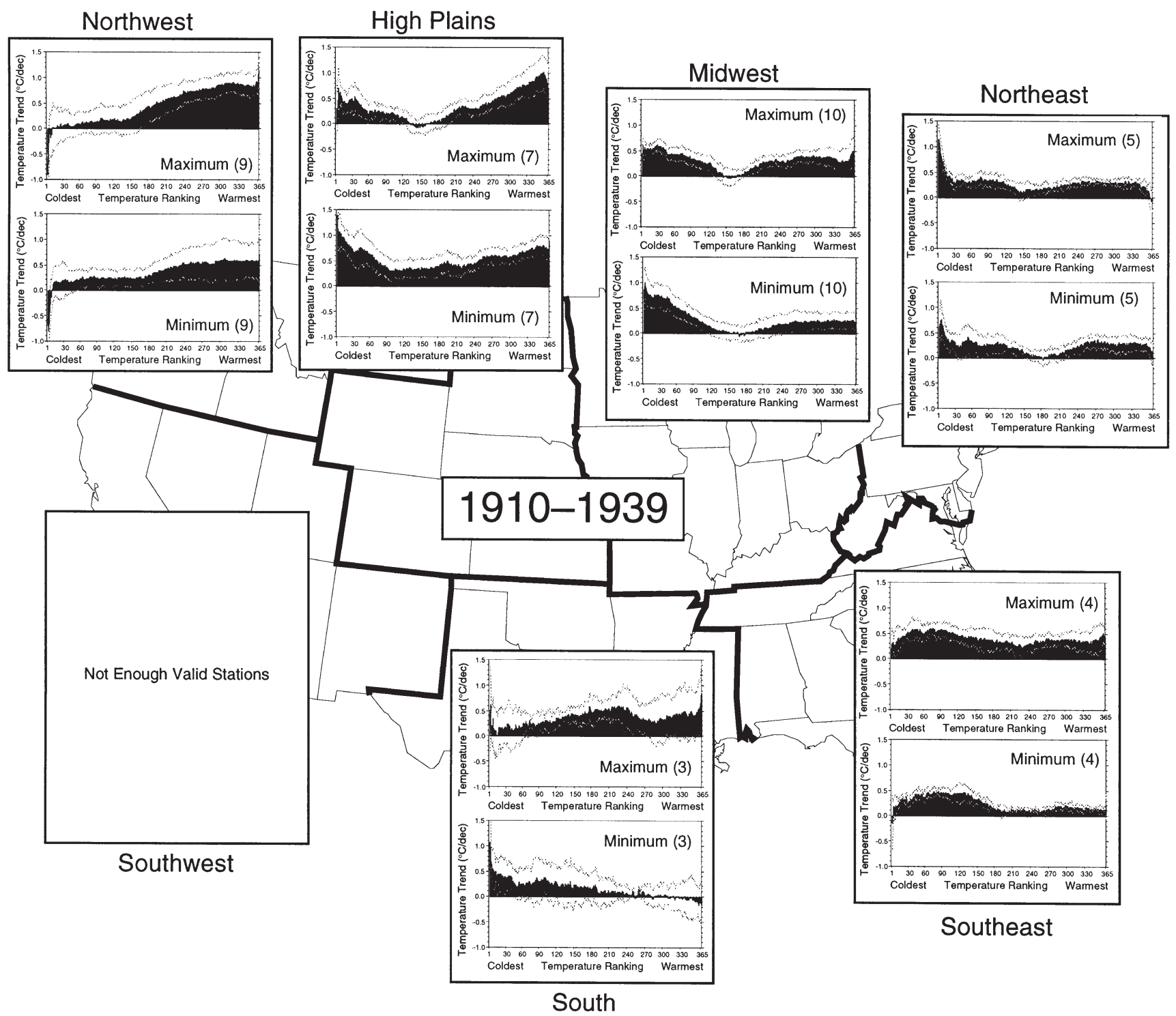

Fig. 2. Regional average trends through ranked daily maximum and minimum temperatures for the period 1910-1939. In parentheses are the numbers of stations within each region used in the analysis. The vertical bars represent the average trend for each ranked day across each station in the region, sorted from coldest to warmest ( $x$-axis), while the thin black lines represent the upper and lower $95 \%$ CLs of this average as defined by 2 SEM 
temperatures. The seasonality of the urban signal is not well established. Some researchers have found that the minimum temperatures during the summer and fall months exhibit the greatest warming (e.g., Ackerman 1985, Karl \& Jones 1989), while others have identified the strongest signal in the winter months (e.g., Balling \& Idso 1989, Moreno-Garcia 1994). In interpreting our results, bear in mind that urbanization effects are likely present, and that they likely act to increase the trends in minimum temperatures over the levels that would be observed in the absence of urban influences.

\section{RESULTS}

\subsection{0-1939}

During the earliest period, 39 stations passed our criteria for inclusion in the analysis of maximum and minimum temperatures. Fig. 2 shows the average temperature trend among all valid stations within each geographic region, along with the $95 \%$ CI as defined by 2 SEM. There was only 1 station in our southwestern region, and, therefore, this region was not included in our subsequent calculations. The trends of ranked daily temperatures showed that a significant warming occurred across most of the remaining 6 regions and across most temperature categories with the exception of the coldest days in the Northwest, and most times of the year in the South (probably due to the small number of valid stations in this region). While the warming was spread throughout the temperature range, there was a tendency for more warming to occur on the warmest days. When the mean trends from the 6 regions were combined (with an equal weighting for each region) into a national average, the country as a whole exhibited an overall significant warming trend in both maximum and minimum temperatures (Fig. 3). The warming trends of minimum temperatures increased toward both the colder and the warmer ends of the ranking, while the trends in maximum temperatures increased more toward the warmest half of the temperature ranking. This resulted in the greatest warming trends being found in the days with the highest maximum temperature. This is a climatic tendency toward more extreme heat.

\subsection{0-1969}

In contrast to the early period warming, the years from 1940 to 1969, with 99 valid stations, were marked by a general cooling throughout the eastern half of the United States, rather neutral changes in the North-
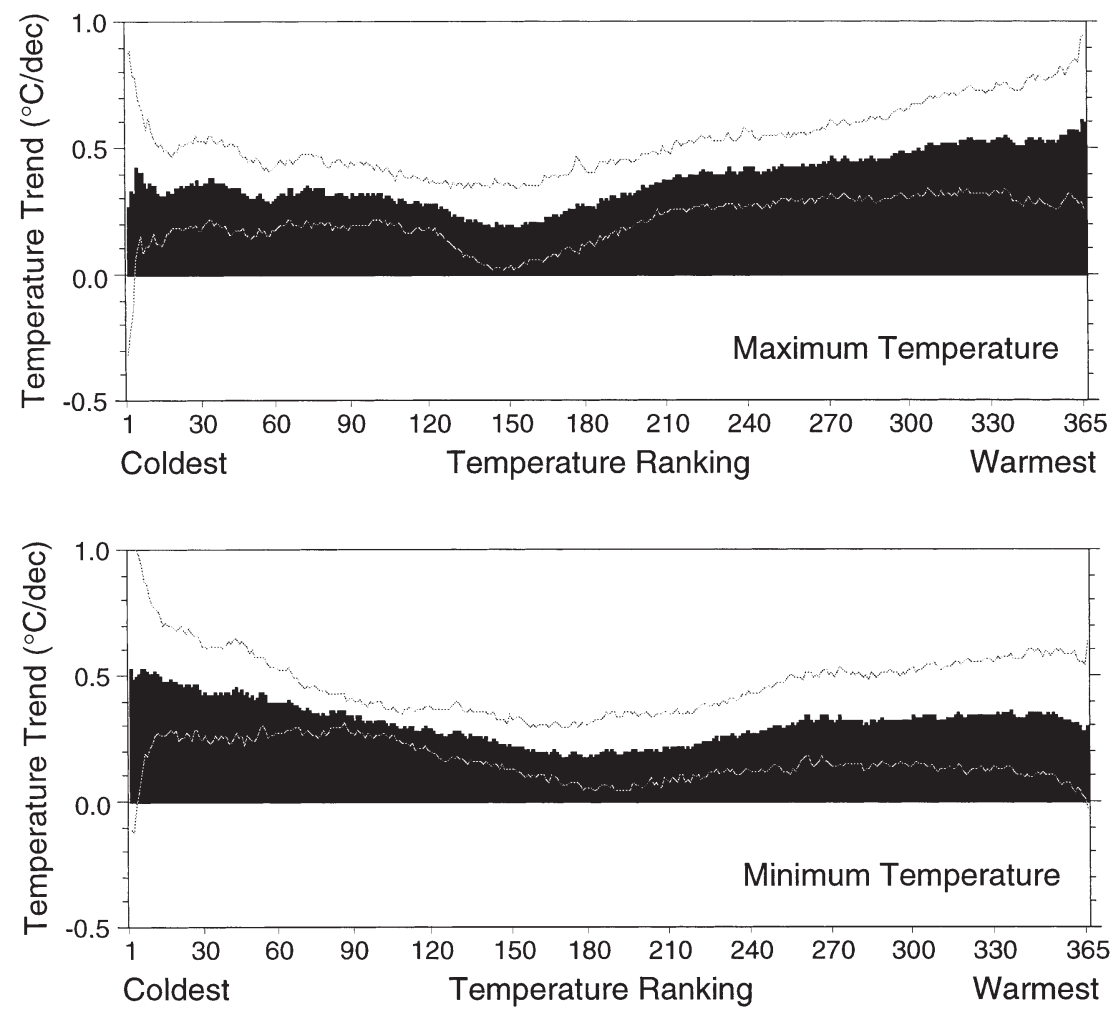

Fig. 3. United States national average trends through ranked daily temperatures for the period 1910-1939. See Fig. 2 for definitions 
west, and a small warming in the southwestern region (Fig. 4). There was a tendency for days with lower maximum and lower minimum temperatures to cool at a rate greater than that observed during warmer days. This pattern becomes more obvious when the trends from the 7 regions are averaged (Fig. 5). On a national scale, this period was characterized by a general reduction in both the daily maximum and daily minimum temperatures. A significant cooling trend in daily maxima was found at both ends of the temperature range, while the significant cooling trends in the daily minima were found primarily during the days with the lowest temperatures. In other words, the coldest days became colder.

\subsection{0-1997}

During the period from 1970 to 1997,100 stations met the data inclusion criteria. The primary feature of temperature change during this period was the large warming trend during the coldest days of the year. An examination of the regional trends in temperatures (Fig. 6) shows that the pattern of greatest warming occurring during the days with the lowest minima, and to a large extent days with the lowest maxima, was common to all regions. The days with more moderate temperatures (those in the middle of the temperature rankings) showed a wide variety of change, including warming in the west, mixed trends in the middle por-

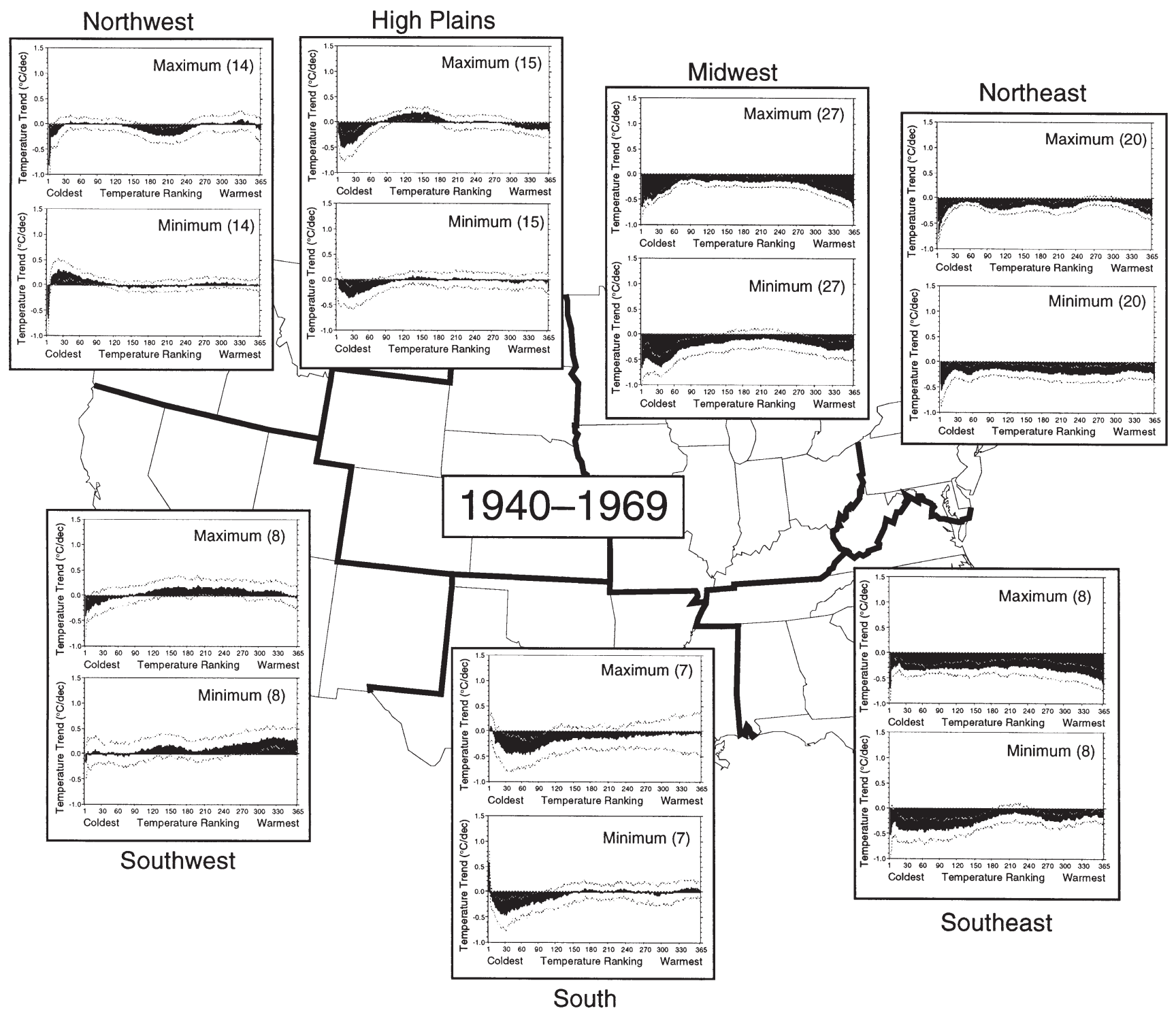

Fig. 4. Regional average trends through ranked daily temperatures for the period 1940-1969. In parenthesis are the numbers of stations within each region used in the analysis. See Fig. 2 for definitions 

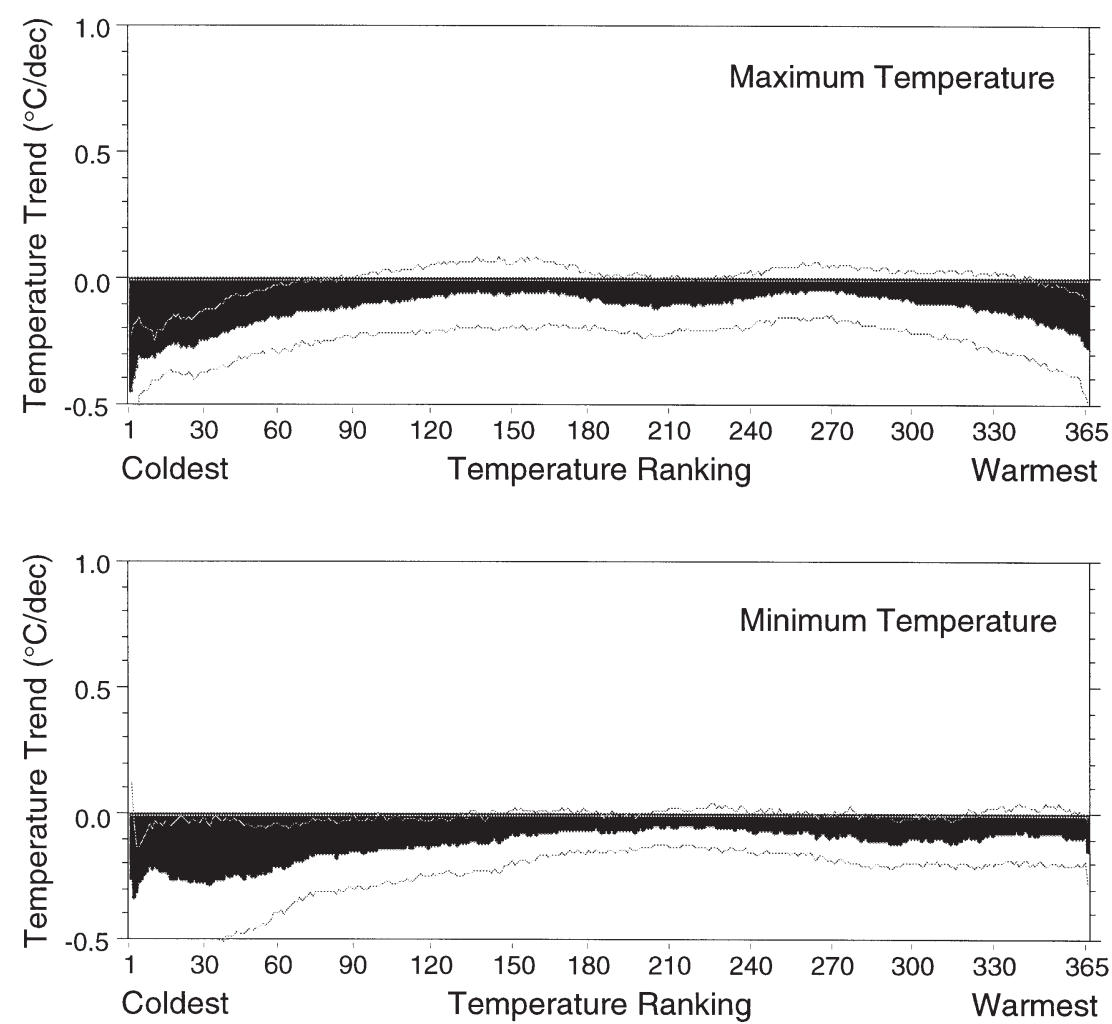

Fig. 5. United States national average trends through ranked daily temperatures for the period 1940-1969. See Fig. 2 for definitions

tions of the country, and cooling in the southeast. The highest daily maximum temperatures exhibited significant increases in the eastern parts of the country and changed little in the western regions. When the 7 regions are combined, the nationwide average trends are dominated by the significant increases during the days with the lowest temperatures (Fig. 7), although increasing temperatures are evident throughout the rankings. This is a climatic tendency characterized primarily by less extreme cold.

These daily results are generally consistent with studies that have investigated changes in minimum and maximum temperatures using data at the monthly time scale (Karl et al. 1991, 1996, Easterling et al. 1997), but provide for a more detailed analysis of the patterns of change.

\subsection{Impact of urbanization}

The impact of urbanization and land-use changes on these daily trends was not quantified in this analysis. As we have previously discussed, there is widespread agreement that urbanization tends to raise minimum temperatures and leave maximum temperatures unaffected, but little agreement as to the seasonality of these changes. Therefore, we assume that, when averaged over a number of stations, urbanization led only to an across-the-year elevation of the trends observed in minimum daily temperatures. We conclude that in the absence of urban influences, the general patterns of temperature changes observed during our 3 study periods would be enhanced. In the 1910-1939 period, the relative dominance of warming on the hottest days would be more pronounced as the positive trends in minimum temperatures would be reduced. During the 1940-1969 period, the cooling trends observed in daily temperature minima would be even greater, and during the 1970-1997 period, urban effects would have little impact on the finding that the greatest warming rate occurred at the cold end of the rankings, in both maximum and minimum temperatures.

\section{DISCUSSION AND CONCLUSION}

During the most recent period (1970-1997), human changes to the earth-atmosphere system should have exerted their largest influence on temperatures since this corresponds to the time of the greatest rate of atmospheric buildup of greenhouse gases as well as their greatest concentrations. Numerous detection 


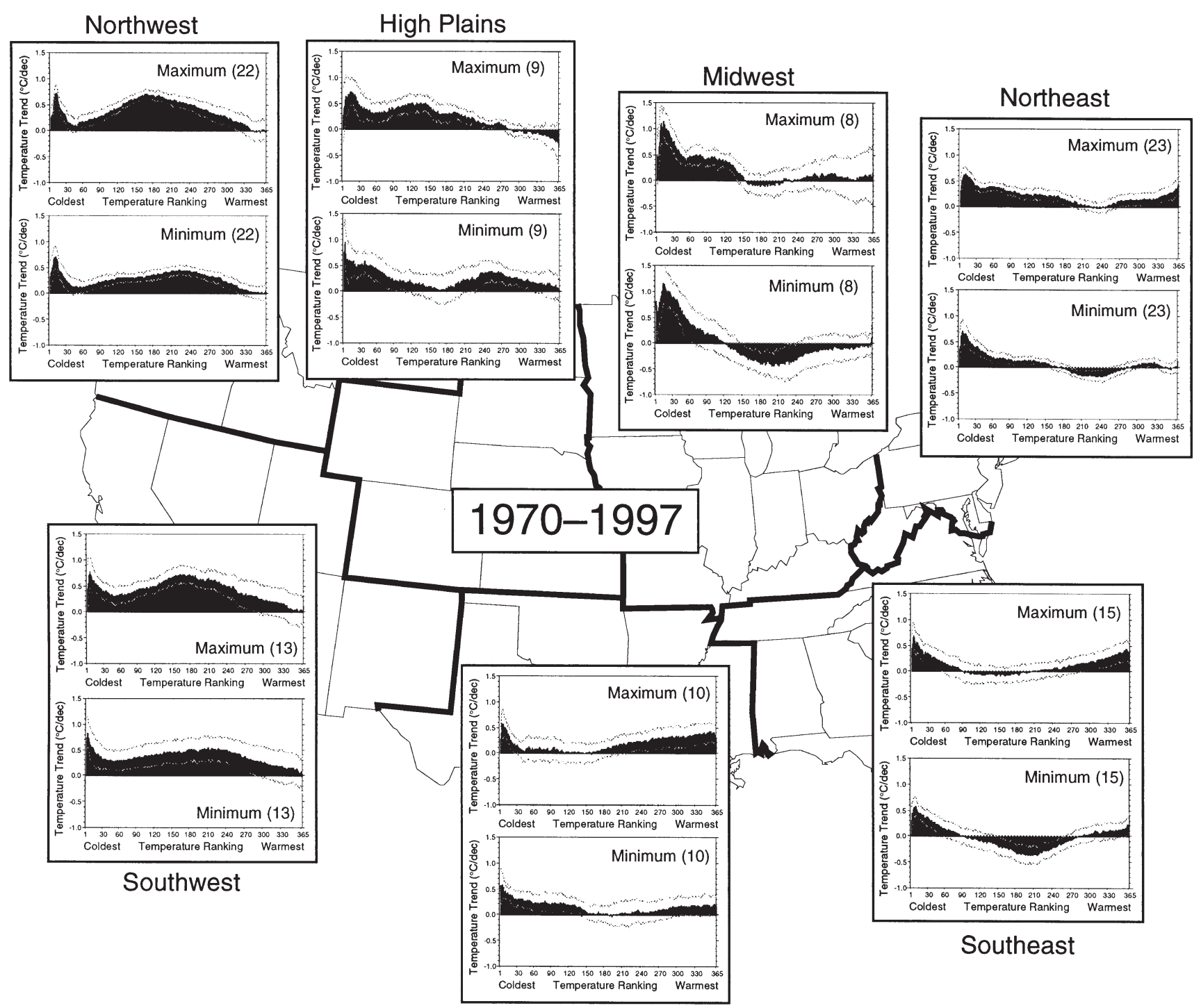

Fig. 6. Regional average trends through ranked daily temperatures for the period 1970-1997. In parenthesis are the numbers of stations within each region used in the analysis. See Fig. 2 for definitions

studies have looked for and reported to have found a connection between observed temperatures and greenhouse gases (e.g., Barnett et al. 1999, Michaels et al. 2000). Our results show that the nature of temperature changes in the United States during this period of warming are quite different from those that occurred during an earlier period of comparable warming with much less human modification of the composition of the atmosphere.

The warming from 1900 to 1939, the period in the last century that had the least anthropogenic influence, was one in which the greatest rise in temperature occurred during the hottest days of the year. The decade at the culmination of the warming, the 1930s, was marked by very hot summer days and extreme and widespread drought conditions across the United States. This early 20th century warming, thought to be predominantly natural and caused by variations in the solar and volcanic output (Lean et al. 1995, Robock \& Free 1995, Lean \& Rind 1998, Crowley 2000), displayed the characteristics of a climate that was becoming more severe. By contrast, the warming observed during the past 3 decades displays few such characteristics. The temperature rise has taken place predominantly in the days of the year with some of the lowest maximum and minimum temperatures, while the days with the highest temperatures have exhibited far less of an increase. These findings add to the growing evidence (Balling et al. 1998, Michaels et al. 1998, Michaels et al. 2000) that the surface air temperature 

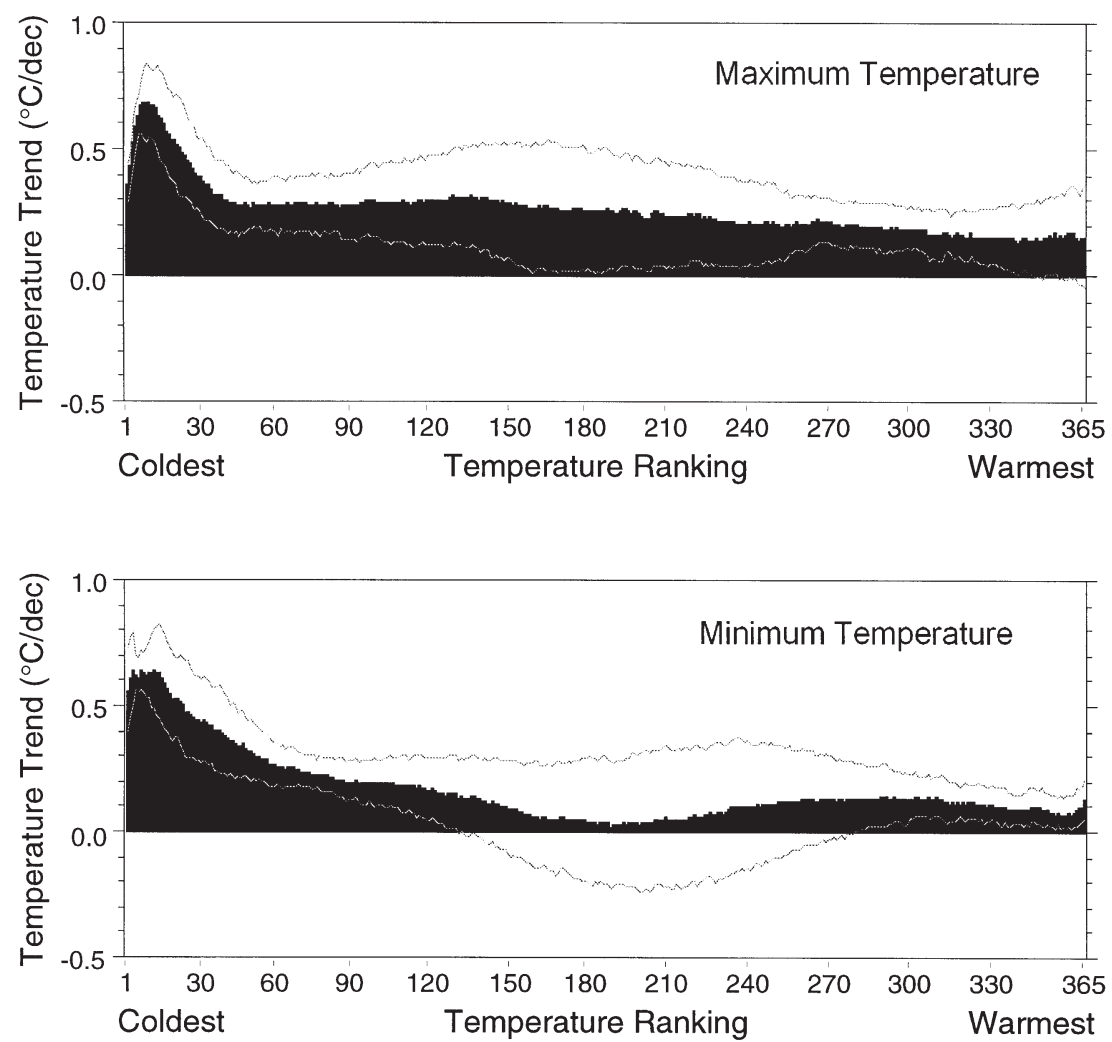

Fig. 7. United States national average trends through ranked daily temperatures for the period 1970-1997. See Fig. 2 for definitions

change that has occurred during the period of the greatest human influence on the climate is one in which increases of extremely low temperatures have dominated over those of high temperatures - a climate tending toward moderation rather than the extreme. Prognostications of dire consequences built upon model projections of a climate change dominated by increasing high temperatures should be reassessed based upon a growing body of evidence to the contrary.

\section{LITERATURE CITED}

Ackerman B (1985) Temporal march of the Chicago heat island. J Clim Appl Meteorol 24:547-554

Baker DG (1975) Effect of observation time on mean temperature estimation. J Appl Meteorol 14:471-476

Balling RC, Idso SB (1989) Historical temperature trends in the United States and the effect of urban population growth. J Geophy Res 94:3359-3363

Balling RC, Michaels PJ, Knappenberger PC (1998) Analysis of winter and summer warming rates in gridded temperature timeseries. Clim Res 9:175-181

Barnett TP and 10 others (1999) Detection and attribution of recent climate change: a status report. Bull Am Meteorol Soc 80:2631-2659
Crowley TJ (2000) Causes of climate change over the past 1000 years. Science 289:270-277

Easterling DR and 10 others (1997) Maximum and minimum temperature trends for the globe. Science 277:364-367

Easterling DR, Karl TR, Lawrimore JH, Del Greco SA (1999) United States Historical Climatology Network Daily temperature, precipitation, and snow data for 1871-1997 ORNL/CDIAC-118, NDP-070. Carbon Dioxide Information Analysis Center, Oak Ridge National Laboratory, Oak Ridge

Easterling DR, Evans JL, Groisman PYa, Karl TR, Kunkel KE, Ambenje P (2000) Observed variability and trends in extreme climate events: a brief review. Bull Am Meteorol Soc 81:417-425

Gallo KP, Owen TW, Easterling DR, Jameson PF (1999) Temperature trends of U.S. historical climatology network based on satellite-designated land use/land cover. J Clim 12:1344-1348

Hughes PY, Mason EH, Karl TR, Bower WA (1992) United States Historical Climatology Network Daily temperature and precipitation data ORNL/CDIAC-50, NDP-042. Carbon Dioxide Information Analysis Center, Oak Ridge National Laboratory, Oak Ridge

IPCC (Intergovernmental Panel on Climate Change) (1996) Climate change 1995: the science of climate change. Contribution of Working Group I. In: Houghton JT, Meira Filho LG, Callander BA, Harris N, Kattenberg A, Maskell K (eds) Second Assessment Report of the Intergovernmental Panel on Climate Change. Cambridge University Press, Cambridge 
IPCC (Intergovernmental Panel on Climate Change) (2001) Climate change 2001: the scientific basis. Contribution of Working Group I to the Third Assessment Report of the Intergovernmental Panel on Climate Change. Available at www.ipcc.ch

Karl TR, Jones PD (1989) Urban bias in area-averaged surface air temperature trends. Bull Am Meteorol Soc 70:265-270

Karl TR, Williams CN, Young J, Wendland WM (1986) A model to estimate the time of observation bias associated with monthly mean maximum, minimum and mean temperatures for the United States. J Clim Appl Meteorol 25: $145-160$

Karl TR, Diaz HF, Kukla H (1988) Urbanization: its detection and effect in the United States climate record. J Clim 1: 1099-1123

Karl TR and 7 others (1991) Global warming: evidence for asymmetric diurnal temperature change. Geophys Res Lett 18:2253-2258

Karl TR, Knight RW, Easterling DR, Quayle RG (1995) Trends in US climate during the twentieth century. Consequences $1: 2-12$

Karl TR, Knight RW, Easterling DR, Quayle RG (1996) Indices of climate change for the United States. Bull Am Meteorol Soc 77:279-292

Landsberg HE (1981) The urban climate. Academic Press, New York

Lean J, Rind D (1998) Climate forcing by changing solar radiation. J Clim 11:3069-3094

Lean J, Beer J, Bradley R (1995) Reconstruction of solar irradiance since 1610: implications for climate change. Geophys Res Lett 22:3195-3198

Editorial responsibility: Chris de Freitas, Auckland, New Zealand
Mann ME, Bradley RS, Hughes MK (1998) Global-scale temperature patterns and climate forcing over the past six centuries. Nature 392:779-787

Michaels PJ, Balling RC, Vose RS, Knappenberger PC (1998) Analysis of trends in the variability of daily and monthly historical temperature measurements. Clim Res 10:27-33

Michaels PJ, Knappenberger PC, Balling RC, Davis RE (2000) Observed warming in cold anticyclones. Clim Res 14:1-6

Moreno-Garcia MC (1994) Intensity and form of the urban heat island in Barcelona. Int J Meteorol 14:705-710

Oke TR (1987) Boundary layer climates. Cambridge University Press, Boston

Quayle RG, Easterling DR, Karl TR, Hughes PY (1991) Effects of recent thermometer changes in the cooperative station network. Bull Am Meteorol Soc 72:1718-1723

Robock A, Free MP (1995) Ice cores as an index of global volcanism from 1850 to present. J Geophys Res 100: 11549-11567

Schaal LA, Dale RF (1977) Time of observation temperature bias and 'climatic change.' J Appl Meteorol 16:215-222

Stott PA, Tett SFB, Jones GS, Allen MR, Mitchell JFB, Jenkins GJ (2000) External control of 20th century temperature by natural and anthropogenic forcings. Science 290: 2133-2137

Tett SFB, Stott PA, Allen MR, Ingram WJ, Mitchell JFB (1999) Causes of twentieth-century temperature change near the Earth's surface. Nature 399:569-572

USNA (United States National Assessment) (2000) Climate change impacts on the United States: the potential consequences of climate variability and change. US Global Change Research Program, Washington, DC

Submitted: October 20, 2000; Accepted: March 20, 2001 Proofs received from author(s): June 14, 2001 